\title{
Progress in the Production of Hot-Gas Filtered Biocrude Oil at NREL
}

J.P. Diebold, J.W. Scahill, S. Czernik, S.D. Phillips, C.J. Feik

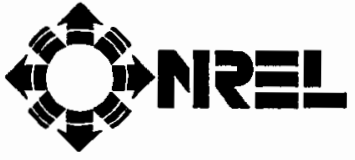

National Renewable Energy Laboratory 1617 Cole Boulevard Golden, Colorado 80401-3393

A national laboratory of the U.S. Department of Energy Managed by the Midwest Research Institute for the U.S. Department of Energy under Contract No. DE-AC36-83CH10093

Prepared under Task No. BF525431

May 1995 


\section{NOTICE}

This report was prepared as an account of work sponsored by an agency of the United States government. Neither the United States government nor any agency thereof, nor any of their employees, makes any warranty, express or implied, or assumes any legal liability or responsibility for the accuracy, completeness, or usefulness of any information, apparatus, product, or process disclosed, or represents that its use would not infringe privately owned rights. Reference herein to any specific commercial product, process, or service by trade name, trademark, manufacturer, or otherwise does not necessarily constitute or imply its endorsement, recommendation, or favoring by the United States government or any agency thereof. The views and opinions of authors expressed herein do not necessarily state or reflect those of the United States government or any agency thereof.

Available to DOE and DOE contractors from:

Office of Scientific and Technical Information (OSTI)

P.O. Box 62

Oak Ridge, TN 37831

Prices available by calling (615) $576-8401$

Available to the public from:

National Technical Information Service (NTIS)

U.S. Department of Commerce

5285 Port Royal Road

Springfield, VA 22161

(703) $487-4650$

\footnotetext{
Printed on paper containing at least $50 \%$ wastepaper, including $10 \%$ postconsumer waste
} 


\title{
PROGRESS IN THE PRODUCTION OF HOT-GAS FILTERED BIOCRUDE OIL AT NREL
}

\author{
J.P. Diebold, J.W. Scahill, S. Czernik, S.D. Phillips, C.J. Feik \\ National Renewable Energy Laboratory \\ Golden, CO 80401
}

\begin{abstract}
Progress in the production of hot-gas filtered biocrude oils from a dry hybrid poplar feedstock in the NREL vortex ablative pyrolysis reactor is discussed. In particular, adjusting the pyrolysis severity in the vortex reactor and the cracking severity in the char baghouse resulted in increased oil yields of very low-ash and low-alkali biocrude oils. The viscosity of these oils meets the requirements for American Society for Testing and Materials (ASTM) \#4 fuel oils. Increasing the water content to $30 \%$ decreased the viscosity by half, but not enough to meet the viscosity requirement for ASTM \#2 fuel oil. Viscosity contours for water and methanol dilution are shown. The addition of water or methanol or both to make a more consistent product may be advantageous. Aging studies of this low-alkali oil showed a slower increase in viscosity with time equal to one-third the rate of a biocrude oil with higher alkali contents. It appears that removal of the char fines results in a more stable oil. In fact, after 24 hours at $90^{\circ} \mathrm{C}$, the viscosity of this low-ash biocrude oil was lower than that seen previously for the unaged sample of higher ash oil. It is concluded that the removal of char fines to produce a premium biocrude oil will be even more important than was previously supposed.
\end{abstract}

\section{INTRODUCTION}

The economics of the production of biocrude oil is very heavily affected by the feedstock costs, capital costs, operating costs, and yields. To some extent, these costs are a function of feedstock preparation required, pyrolysis reactor design, location, and plant size. These parameters have been the subject of many economic studies (e.g., Cottam and Bridgwater 1994; Beckman et al. 1990) and will not be discussed here.

However, the other half of the economic story is the market value of the products. With petroleum crude oils, crude oils high in metals, high in sulfur, or low in hydrogen are worth less than what are considered premium crude oils. Most economic studies consider biocrude oil to have only an energy value equal to residual fuel oil, e.g., ASTM \#6 fuel oil. However, \#6 fuel oil has a relatively low economic value because it is viscous and is high in sulphur, metals, and ash. To burn heavy fuel oil requires specialized combustion and flue gas equipment to reduce sulfur and ash emissions.

In Table 1, the tax-free prices paid by consumers for diesel fuel, light fuel oil, and heavy fuel oil are listed for several western European countries, Canada, and the U.S. (adapted from Tippee and Beck). There are significant differences in the tax-free costs of these fuels. Some of these differences in 
costs from country to country may be due to different specifications for the fuels or due to different abilities of the refineries to meet the local supply and demand. In any case, the relative tax-free cost to the consumer of diesel relative to that of heavy fuel oil is seen to vary from 3.2 in the United Kingdom to 2.0 in the United States. The relative tax-free cost of light fuel oil to that of heavy fuel oil varies from 2.4 in France to 1.5 in the United States.

Table 1

1993 Tax-free Consumer Prices for Diesel, Light Fuel Oil, and Heavy Fuel Oil

\begin{tabular}{|c|c|c|c|c|c|}
\hline Country & $\begin{array}{l}\text { Diesel, } \\
\text { US\$/L }\end{array}$ & $\begin{array}{l}\text { LFO, } \\
\text { US } \$ / \mathrm{L}\end{array}$ & $\begin{array}{l}\text { HFO, } \\
\text { US } \$ / L\end{array}$ & Diesel/HFO & LFO/HFO \\
\hline Canada & 0.24 & 0.15 & 0.10 & 2.4 & 1.6 \\
\hline Finland & 0.24 & 0.18 & 0.10 & 2.4 & 1.8 \\
\hline France & 0.21 & 0.17 & 0.07 & 2.9 & 2.4 \\
\hline Germany & 0.22 & 0.18 & 0.09 & 2.4 & 2.0 \\
\hline Italy & 0.22 & 0.21 & 0.11 & 2.0 & 1.9 \\
\hline U.K. & 0.25 & $0.15^{*}$ & 0.08 & 3.2 & 1.9 \\
\hline U.S. & 0.19 & 0.15 & 0.10 & 2.0 & 1.5 \\
\hline
\end{tabular}

* 1992 LFO price

The value of the product heavily impacts the profit of a process. The profit of a biocrude oil process for energy production is given by:

$$
\text { Profit }=\Sigma\left[(\text { Product Yield, } \mathrm{kg})_{\mathrm{i}}(\mathrm{LHV}, \mathrm{MJ} / \mathrm{kg})_{\mathrm{i}}(\text { Product Value, } \$ \mathrm{MJ})_{\mathrm{i}}\right]-\Sigma \text { Costs, }
$$

where LHV is the lower heating value of the wet oil as delivered. As seen in this equation, the profit can be increased by an increase in value of the product, if any decrease in yield is proportionately smaller. Let us assume that the energy contents of the different grades of petroleum fuel oils are about the same. From Table 1, the gross economics of making a light fuel oil, rather than a heavy fuel oil, is equivalent to a $150 \%$ yield increase of heavy fuel oil production (in the United States). Another perspective is that in the United States, the yield of the light fuel oil could be reduced by nearly a third and still be economically advantageous over making a heavy fuel oil. These effects are even more favorable for light fuel relative to heavy fuel in all of the other countries listed in Table 1.

Also as seen in Table 1, the economic advantages of producing diesel fuel, rather than a heavy fuel oil, are even more pronounced. For example, if one could make a premium biocrude product that could be burned as a diesel fuel, it would be economically equivalent to a $200 \%$ increase in heavier biocrude yields usable only as a heavy fuel oil (in the United States). From another perspective, the economics would still be enhanced if the yield of biocrude diesel were only a little over half of the 
heavy fuel oil yield for the same tax-free economics. Again, this economically allowable loss in biocrude yields to produce a diesel fuel is higher in the other countries listed in Table 1.

In Table 2 are listed the total price and the included taxes paid by the customer in several different countries for diesel, light fuel oil, and heavy fuel oil (adapted from Tippee and Beck). Table 2 reveals that diesel fuel is taxed at much higher rates than is light fuel oil or heavy fuel oil. In Europe, light fuel oil is taxed more than heavy fuel oil; heavy fuel oil taxes are typically very small. Canada and the United States tax neither light nor heavy fuel oils. Italy is the only country listed that has a high tax on light fuel oil--nearly as much as on diesel fuel. As seen in Table 2, the total cost of light fuel oil, relative to heavy fuel oil, varies from 1.5 in the U.S. to 4.4 in Italy. The total cost of diesel fuel relative to heavy fuel oil varies from 3.1 in the United States to 6.7 in the United Kingdom.

Table 2

Total Price Paid by Consumers (Included Taxes)

\begin{tabular}{||l|c|c|c|c|c||}
\hline \hline Country & $\begin{array}{c}\text { Diesel, } \\
\text { US } \$ / \mathrm{L}\end{array}$ & $\begin{array}{c}\text { LFO, } \\
\text { US } \$ / \mathrm{L}\end{array}$ & $\begin{array}{c}\text { HFO, } \\
\text { US } \$ / \mathrm{L}\end{array}$ & Diesel/HFO & LFO/HFO \\
\hline Canada & $0.39(0.16)$ & $0.15(0)$ & $0.10(0)$ & 4.0 & 1.6 \\
\hline Finland & $0.52(0.28)$ & $0.21(0.01)$ & $0.12(0.01)$ & 4.3 & 1.8 \\
\hline France & $0.53(0.31)$ & $0.25(0.08)$ & $0.10(0.02)$ & 5.5 & 2.6 \\
\hline Germany & $0.54(0.32)$ & $0.23(0.05)$ & $0.11(0.02)$ & 5.0 & 2.1 \\
\hline Italy & $0.61(0.39)$ & $0.59(0.38)$ & $0.13(0.02)$ & 4.5 & 4.4 \\
\hline U.K. & $0.62(0.37)$ & $0.17^{*}(0.02)$ & $0.09(0.01)$ & 6.7 & 1.9 \\
\hline U.S. & $0.30(0.11)$ & $0.15(0)$ & $0.10(0)$ & 3.1 & 1.5 \\
\hline
\end{tabular}

* 1992 LFO price

In an effort to subsidize the production of liquid fuels from biomass, it is understood that some countries will, or may in the future, choose to reduce or forgive these fuel taxes. The amount of this tax incentive would vary from country to country, but potentially would be more substantial in Europe than in North America. As seen in Table 2, this tax incentive would be an additional incentive to produce a higher quality of biocrude oil over and above that of heavy fuel oil, because the potential tax break for heavy fuel oil would be very small. This is particularly true in Italy, where light fuel oil is taxed at the same high rate as diesel fuel.

In summary, the economic incentives to produce a very high quality biocrude oil are very pronounced due to the large differences in the perceived value of different grades of fuel oil. Tax incentives appear to accentuate these differences in value. At NREL, we have been investigating the effect of hot-gas filtration to reduce the alkali metal and char content of the biocrude oil. Although we have observed some loss in biocrude oil yield by the addition of this step, the quality 
of the oil may be increased to the point at which it can be considered to be a low-sulfur, medium to light fuel oil rather than a heavy fuel oil substitute. This increase in quality is due to a lower ash and alkali content, lower viscosities, and improved storage properties.

Filtration of liquid biocrude oils has been attempted (Elliott 1994) but has not been very successful. The oil tends to agglomerate around the particles with subsequent high pressure drops developing across the filter and oil losses due to removal of some of the oil with the char sludge. The submicron char present tends to pass through the liquid filters. In addition to these problems, some recent findings discussed earlier in this report indicate that the presence of char in the oil adversely affects the oil stability (Agblevor et al. 1995). Consequently, we feel that the preferred option is to remove as much char as possible prior to condensation of the oil vapors.

This paper describes the recent efforts at NREL directed toward the process development necessary to be able to produce biocrude oils in high yields with very low alkali metal levels. The ablative vortex pyrolysis reactor at NREL (Diebold and Scahill 1988) was used to produce a pyrolysis stream, from which the char was removed using a hot-gas filter. This unique hot-gas filter can be fitted with either rigid sintered Inconel filter elements made by Memtec or flexible woven Nextel ceramic filter bags made by 3-M. From our limited operational experience, we have chosen to concentrate on the use of the flexible ceramic filter bags, which appear to be easier to backflush. Previous experience had shown that although the hot-gas filtering was effective in removing the char to very low levels, oil yields were lower due to excessive cracking of the vapors in the baghouse (Diebold et al. 1994).

\section{VORTEX REACTOR HOT-GAS FILTRATION STUDIES}

\section{Feedstock}

A hybrid poplar ( $P$. trichocarpa $x$ P. deltoides) was used for all these experiments and is a cross between Black Cottonwood and Eastern Cottonwood. This biomass was obtained from the James River Paper Company and grown on the tree plantation that supplies feed to their pulp mill. The trees were harvested at seven years into their growth cycle and debarked to a level of $1.0 \%$ bark remaining in the final dry chips. This feed is probably typical of that which would be obtained from a dedicated woody biomass energy farm. The chips were knife milled through a $3.2-\mathrm{mm}(1 / 8$-in) screen and bone dried at $105^{\circ} \mathrm{C}$ before feeding to the process. Feedstock analysis data are presented in Tables 4 and 5.

\section{Vortex Reactor Experimental Activities}

Three experimental runs were conducted with the ablative vortex pyrolysis reactor with the objective of operating the baghouse at the lowest possible temperature to demonstrate reasonably high oil yields while maintaining low alkali metal content in the oil. Different approaches were used in lowering the process stream temperature, each giving somewhat different results.

The initial approach to doing this was to lower the exit temperature of the reactor by using a much lower carrier gas temperature in Run 173 . Typically carrier gas temperatures of $700^{\circ} \mathrm{C}$ had been previously used because this generally resulted in good pyrolysis of the biomass. During Run 173, 
carrier temperatures of $430^{\circ} \mathrm{C}$ were used, but this low temperature resulted in incomplete pyrolysis of the biomass feed with corresponding high water yields (14.9\% by weight) and char yields (19.1\%) and relatively low dry oil yields $(35.9 \%)$.

In Run 174, it was decided to return to higher carrier gas temperatures to insure complete pyrolysis and to spray recycled condensates into the transfer line to reduce the temperature between the vortex reactor and the baghouse. This was much more successful in reducing and controlling the baghouse entrance temperature at the desired range. Unfortunately, spraying condensates into the transfer line also resulted in localized cold spots where char/oil condensed to plug the line.

For Run 175, it was decided to remove the bulk of the char before the pyrolysis stream reached the baghouse to determine how this affects the filtration step. This was accomplished by installing two cyclone separators in series just upstream of the baghouse. In this configuration, only the fines were sent to the baghouse so a much thinner cake would be present on the filter. The longer transfer line and cyclones provided enough heat losses to achieve the desired low temperature of the stream entering the baghouse. The overall baghouse temperature was lower during this run. This run had the highest biocrude yields in this series of experiments.

\section{Experimental Results}

Pyrolysis yield results from the three experiments are shown in Tables 3, 4, and 5. As seen in Table 3 , the yields of organic oil progressively improved. The poor yields from Run 173 are a combination of poor conversion of the biomass at the lower carrier gas temperatures and the higher cracking severity the vapors were exposed to in going through the baghouse. The quality of this oil was also poor as a result of the water yield relative to the low organic oil yield, resulting in an oil with $29 \%$ water by weight. This resulted in separation of the biocrude liquid into two approximately equal dark brown phases that were very difficult to distinguish. However, the upper, aqueous rich phase had a noticeably lower viscosity and was considerably richer in water than the bottom phase. Because Run 173 had two phases, it was decided to perform only limited testing on this material.

Better control of the baghouse temperatures in Runs 174 and 175 are reflected in the improved yields for these runs. The condensates from these two runs were verified to be single-phase liquids by determining that the moisture contents of the top and bottom of the oils were the same. The somewhat higher char make in Run 174 is thought to be due to recycling of the condensates back to the high temperature transfer line. In addition to cooling this stream, the recycled condensates were exposed repeatedly to the time, temperature, and char in the baghouse; char is known to catalyze vapor reactions to form char (Mok et al. 1992). The lowest temperatures in the baghouse were seen in Run 175, which, not surprisingly, also had the best oil yields.

\section{Oil Properties}

Elemental analyses of oils from Runs 174 and 175 are shown in Table 4. Shown are both high and low heating values, as well as, the calculated values for "dry" oil without water. The dry oil from Run 174 had a lower oxygen content and a higher heating value than that calculated for the dry oil from Run 175. 
Table 3

Biocrude Yields

\begin{tabular}{|c|c|c|c|}
\hline Run \# & 173 & 174 & 175 \\
\hline $\begin{array}{c}\text { Yields, wt \% Feed } \\
\text { Organic Oil } \\
\text { Water } \\
\text { Char } \\
\text { Gas } \\
\end{array}$ & $\begin{array}{l}35.9 \\
14.9 \\
19.1 \\
22.8 \\
\end{array}$ & $\begin{array}{l}41.0 \\
14.6 \\
16.4 \\
21.7 \\
\end{array}$ & $\begin{array}{l}49.3 \\
12.1 \\
12.2 \\
18.2 \\
\end{array}$ \\
\hline $\begin{array}{c}\text { Product Recovery } \\
\text { wt \% of Feed }\end{array}$ & 92.6 & 93.7 & 91.8 \\
\hline
\end{tabular}

Table 4

Elemental Analyses and heating values of Biocrude Oils and Feedstock

\begin{tabular}{||c|c|c|c|c|c||}
\hline Run \# & 174 & 174 & 175 & 175 & POPLAR \\
\hline $\begin{array}{c}\text { Elemental Analysis } \\
\text { (wt \%) }\end{array}$ & Wet & Dry & Wet & Dry & \\
carbon & 44.6 & 60.5 & 46.5 & 57.3 & 49.0 \\
hydrogen & 7.9 & 6.7 & 7.2 & 6.3 & 6.0 \\
oxygen & 47.3 & 32.6 & 46.1 & 36.2 & 44.1 \\
nitrogen & 0.17 & 0.23 & 0.15 & 0.18 & 0.1 \\
sulfur & 0.02 & 0.0 & 0.02 & 0.02 & 0.03 \\
\hline HHV MJ/kg & 17.8 & 24.1 & 18.6 & 23.0 & 19.5 \\
LHV MJ/kg & 16.1 & 22.7 & 17.0 & 21.6 & 18.2 \\
\hline
\end{tabular}

Alkali metal determinations of Runs 174 and 175 were measured using both instrumental neutron activation (NA) and atomic absorption spectroscopy (AA) analyses. Since Run 173 oil was two phase, the analysis of this oil by AA was susceptible to errors due to inhomogeneity and was therefore not conducted. NA was also considered to be the most accurate because it required no sample preparation. The separate phases from Run 173 were analyzed for alkali using NA; as suspected, alkali levels in the aqueous phase were significantly greater than in the organic phase. The probable presence of multiphase oils in the past can explain why previous analysis of some biocrude oils gave such variable results. However, the results from AA do compare favorably with those from NA in Runs 174 and 175, in which the oil was single phase and more homogeneous. Alkali metal, alkaline earth, and other trace elements in the different oil samples are shown in Table 5. The total alkali level in the oil made in Run 175 is shown to be about 10 ppm, compared to more than $1200 \mathrm{ppm}$ in the poplar feedstock. Some of the sodium in this oil is thought to have been leached from the glass sample container; we are modifying our sampling technique to avoid this source of sodium contamination. This low level of alkali is still 10 times higher than that desired for use in aeroderivative turbine engines (Moses and Bernstein 1994). 
Table 5

Trace Element Content of Biocrude Oils

\begin{tabular}{|c|c|c|c|c|c|c|c|}
\hline Run \# & 173 & $173^{\circ}$ & 174 & 174 & 175 & 175 & Poplar \\
\hline $\begin{array}{r}\text { Element } \\
\text { ppm }\end{array}$ & $\begin{array}{c}\text { NA }^{*} \\
\text { Aqu }\end{array}$ & $\begin{array}{c}\mathrm{NA}^{*} \\
\text { mixed }\end{array}$ & $\mathbf{N A}^{*}$ & $\mathbf{A} \mathbf{A}^{* *}$ & $\mathbf{N A}^{*}$ & $\mathbf{A A}^{\star *}$ & $\mathbf{A A}^{* *}$ \\
\hline Calcium & 13.13 .2 & 11.5 & 2.1 & 2 & 2.2 & 1 & 1550 \\
\hline Potassium & 16.46 .8 & 13.7 & 4.4 & $<10$ & 2.7 & $<5$ & 1200 \\
\hline Sodium & $27.2 \quad 4.5$ & 28.6 & 7.3 & 7.0 & 7.2 & 11 & 27 \\
\hline Magnesium & & & 8.5 & & & & \\
\hline Chlorine & & & 8.1 & & 7.9 & & \\
\hline Aluminum & & & 2.5 & & 2.6 & & \\
\hline Titanium & & & 0.3 & & $<0.2$ & & \\
\hline Vanadium & & & 0.004 & & 0.002 & & \\
\hline Manganese & & & 0.072 & & 0.063 & & \\
\hline
\end{tabular}

${ }^{*} \mathrm{NA}=$ Neutron Activation; ${ }^{* *} \mathrm{AA}=$ Atomic Absorption

Figure 1 shows the effect of temperature on viscosity for unaged biocrude oils from Runs 174 and 175. Also shown are the viscosity ranges specified for ASTM \#2 and \#4 diesel and fuel oils at $40^{\circ} \mathrm{C}$. It is seen that these biocrude oils initially met the viscosity specification for $\# 4$ diesel and fuel oils. Note that the oil made in Run 174 had a higher water content and a lower viscosity.

Accelerated aging tests of biocrude from Run 175 were conducted at $37^{\circ}, 60^{\circ}$, and $90^{\circ} \mathrm{C}$. Data for the $90^{\circ} \mathrm{C}$ aging tests are shown in Figure 2. For comparison, an oak oil that had been made using only cyclones to remove the char and aged at the same condition is also shown. It is seen that the poplar oil was considerably lower in viscosity initially and had a rate of viscosity increase that was about one-third that of the oak oil. The lower initial viscosity of the poplar oil is due to a combination of more severe pyrolysis conditions, higher water content, different feedstocks, and possibly to better collection of the volatiles. At the end of 24 hours at $90^{\circ} \mathrm{C}$, the viscosity of the poplar oil was less than the initial viscosity of the oak oil.

\section{DISCUSSION}

\section{Aging of the Biocrude Oil}

The reason for the slower rate of aging with the Run 175 oil is speculated to be primarily related to the lower char and alkali content of the poplar oil, although oak oil may age inherently faster than poplar oil. The oak oil had been produced using char cyclones to remove the char, but not with the 
baghouse as was the case in Run 175. Recent work at NREL has shown that adding char to biocrude oil will drastically increase its rate of aging and result in early phase separation (Agblevor et al. 1995). This catalytic effect of the char is thought to be related to the concentration of alkali in the char, but surface effects of the char fines may also be involved. The aging data suggest that this low-ash poplar oil can be safely preheated to $90^{\circ} \mathrm{C}$ to reduce viscosity for better atomization and combustion--if held at that temperature for less than a few hours.

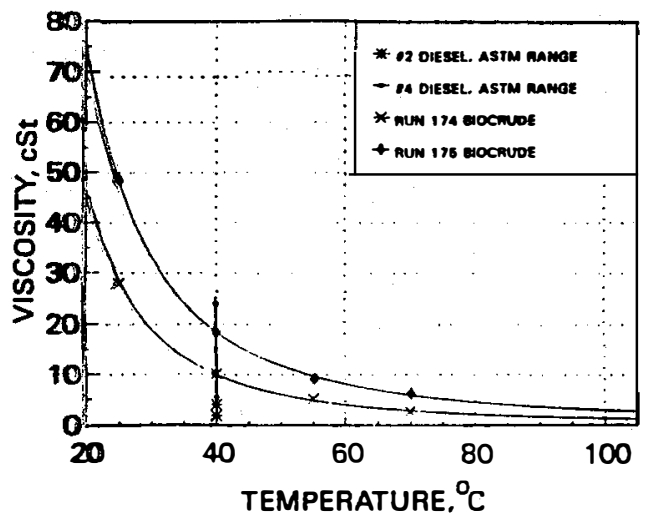

Figure 1. Initial Viscosity of Biocrude Oils from Runs 174 and 175

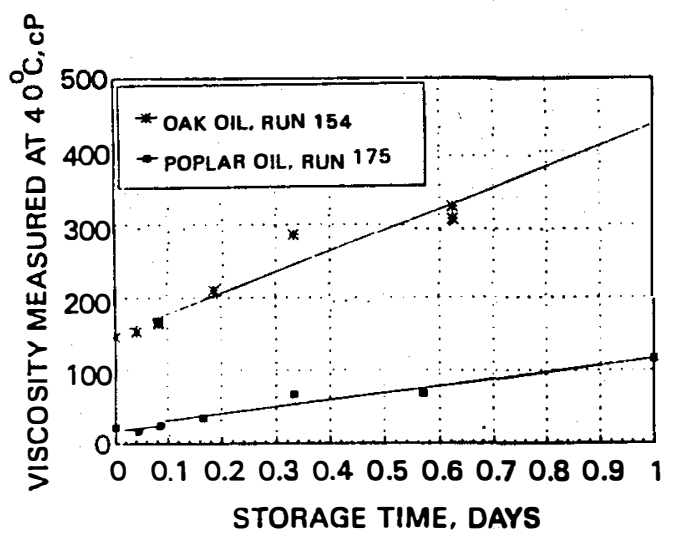

Figure 2. $\quad$ Aging of Run 175 Biocrude Oil at $90^{\circ} \mathrm{C}$

\section{Water Content of Biocrude Oils}

The water found in biocrude oils comes from two sources: (1) the pyrolysis or chemically formed water, and (2) the moisture that was present in the feedstock. The water formed during pyrolysis is formed by dehydration reactions, which for the most part are related to the char-forming reactions. The amount of char formed is partly a function of the alkali metal content of the feed and of process variables that are primarily set by the pyrolysis configuration. Factors known to affect the char yield include extent of partial pyrolysis, heating rate, char recovery from the vapor stream, inorganic content, and final char temperature. The char and water formation are not easily manipulated over large ranges in fast pyrolysis.

However, the moisture in the feedstock is easily controlled by the extent of drying prior to pyrolysis. Most of the pyrolysis data reported in the literature are for feed that has been dried to about $5 \%$ to $10 \%$ moisture by weight. NREL is relatively unique in that we oven dry our feedstock at $105^{\circ} \mathrm{C}$ prior to pyrolysis. By oven drying our feedstock, we significantly reduce the energy required for pyrolysis and also produce a relatively drier biocrude oil.

In comparing biocrude yields, great care needs to be taken to have consistent bases. For example, in Run 175, the yield of dry biocrude oil was $49.3 \%$ by weight of the oven-dried feedstock, whereas the yield of wet biocrude oil was $61.4 \%$ of the oven-dried feedstock. For comparison, consider the case of wood counter-currently dried at $25^{\circ} \mathrm{C}$ with air having $47 \%$ relative humidity, which has an equilibrium moisture content of $8.6 \mathrm{~g}$ water per $100 \mathrm{~g}$ dry wood (Siau 1984). If this wet feedstock had been used for Run 175, the calculated yield of wet biocrude oil would have been $70 \%$ by weight on a "dry" feedstock basis (but without correcting for the moisture in the feed that appears as moisture in the oil). In this hypothetical case, the wet biocrude oil (as produced) would have 
contained $30 \%$ moisture by weight, rather than the $19.7 \%$ moisture we actually observed using ovendried feed. Allowing char fines in the oil increases the apparent oil yields slightly, the heating value, and the ash content. Only by comparing biocrude oils having similar char and moisture contents can valid comparisons be made of heating values, wet oil yields, and viscosities to reveal the real differences in the oils due to the feedstock and the process conditions employed.

The operator of a pyrolysis plant will probably purchase wet feedstock from the grower on a moisture-free basis. The pyrolysis plant operator would then dry it to a moisture level that he can process and produce an acceptable biocrude product. Other things being equal, the capacity of the pyrolysis plant will increase as the moisture level of the feed decreases, due to the relatively large latent heat of vaporization of water compared to the heat required for pyrolysis. It is expected that the biocrude will be sold on an energy basis (LHV). Because the LHV decreases with an increase in water content, it will not be advantageous to have a high water content in the oil except to lower the viscosity to an acceptable value for good pumping and atomization prior to combustion. Too much water will cause the biocrude to separate into two phases, a thin aqueous phase and a thick tar phase.

If the water vapor is not cocondensed with the biocrude oil, large losses in biocrude oil yield and quality would be expected due to the loss of the organic volatiles. Loss of these volatile causes the viscosity of such a biocrude to be very high due to the low viscosity of these solvents. The effects of moisture on the viscosity of the biocrude oil is shown in Figure 3. A decrease in viscosity from $4000 \mathrm{cP}$ to $14 \mathrm{cP}$ is shown for two oils to which water had been added to create a range in moisture from $6.7 \%$ to $30 \%$ by weight. Run 129 oil was made from Southern Pine at similar vortex reactor conditions as Run 175 , but with char removal with cyclones and apparently at a higher temperature in the condensation train. It is thought that the oil from Run 175 has a lower viscosity than would be extrapolated from the data for the oil from Run 129, because more organic volatiles or solvents were probably cocondensed with the increased water content in the oil of Run 175. The difference in feedstocks may also play a role in the differences in the viscosity of the two oils. The addition of a solvent like methanol can lower the viscosity of the Run 175 oil even further, as is also shown in Figure 3.

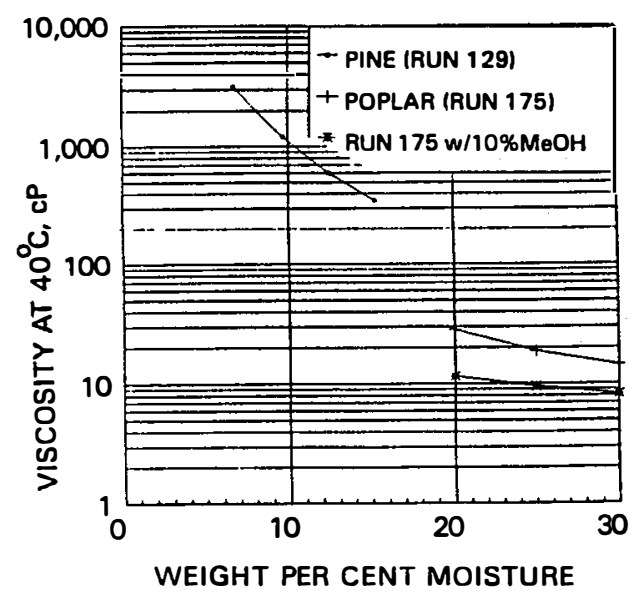

Figure 3. Effect of moisture in biocrude oil on viscosity 
Based on the literature reported for biocrude oils produced by Ensyn (Bakhshi and Adjaye 1994) and Union Fenosa (Cuevas et al. 1994), it is expected that biocrude oils will have moisture contents of $15 \%$ to $30 \%$ by weight in production. This variable moisture content will be a function of the moisture in their partially dried feedstocks and to variations in the amount of volatiles and water recovered by the condensation train. Consequently, a biocrude specification that can be easily met will need to allow a moisture content somewhere in this range. Methanol could be added to adjust the viscosity with minimal affect on the LHV, as it would be a relatively inexpensive fuel additive. Figures $4 \mathrm{a}$ and $4 \mathrm{~b}$ show the viscosity for Run 175 oil at different moisture and methanol contents; it is seen that both water and methanol act as solvents, with the lower density methanol slightly more effective on a weight basis. The relative volumes of the solvents appear to be driving the decrease in viscosity of the mixture. In Figure 4a, it is seen that the effect of added water or methanol or both is to reduce the temperature dependence of viscosity. At high temperatures, the viscosities are all within a few centipoises of each other. The viscosity of Run 175 oil was initially within the viscosity specifications of ASTM \#4 fuel oils, requiring a viscosity of between 5.5 and $40 \mathrm{cSt}$ $(\mathrm{cSt}=\mathrm{cP} /$ density $)$.

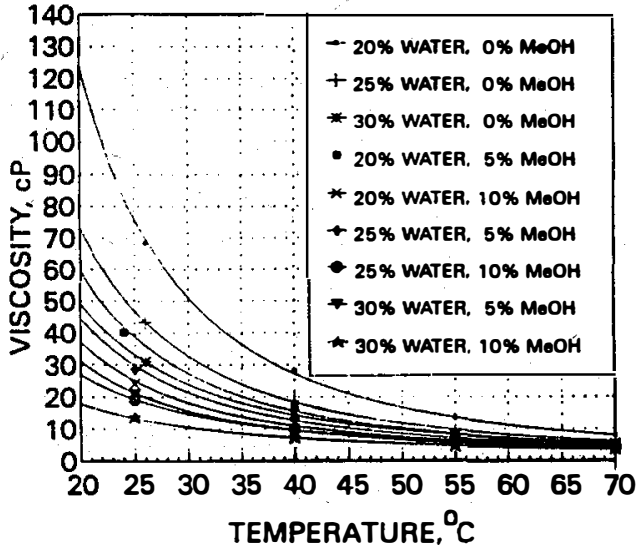

Figure 4a. Combined effect of moisture and methanol on viscosity of Run 175 biocrude oil at $40^{\circ} \mathrm{C}$

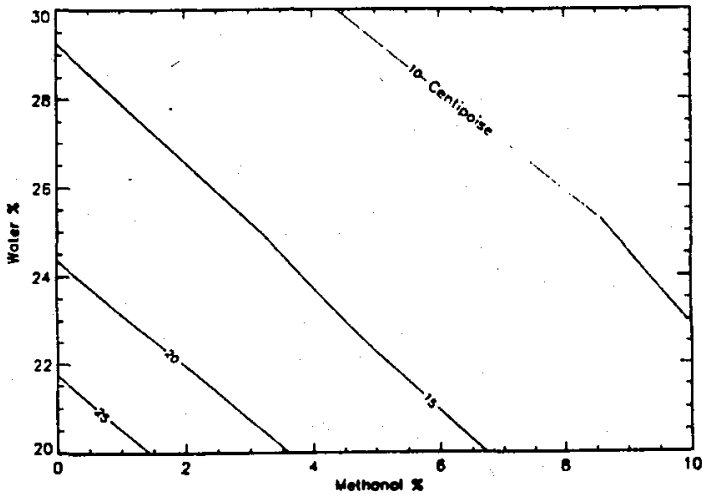

Figure 4b. Combined effect of moisture and methanol on viscosity of Run 175 biocrude oil at $40^{\circ} \mathrm{C}$

The Higher Heating Value (HHV) and Lower Heating Value (LHV) of a biocrude oil are theoretically linear functions of the moisture content. For example, an oak oil from a previous run (Run 154), having a moisture content of $16 \%$ by weight, is shown in Figure 5. The HHV is seen to be very well predicted by the curve based on data for another oak oil (Run 140) containing nearly $39 \%$ by weight of water. Much of the variability of the reported heating values of biocrude is due to the large differences possible in the moisture content of the biocrude oil (10\% to $40 \%)$, as well as to the inconsistency of reporting the heating value on a dry oil basis or on an as-produced-basis (wet).

Because the moisture content affects the heating value of the wet oil, it also affects the adiabatic flame temperature. The flame temperature is important because the available heat from the combustion is proportional to the difference between the flame temperature and the temperature of the exiting flue gases. The exiting flue gas temperature is a function of the heat recovery equipment and can be considered to be constant for the purpose of discussion here. The relationship between the calculated adiabatic flame temperature and the moisture content of the wet biocrude at 
stoichiometric conditions ( $0 \%$ excess air) is shown in Figure 6 . The combustion air was at $25^{\circ} \mathrm{C}$; combustion products were assumed to be only nitrogen, water vapor, and carbon dioxide; the heat of vaporization of the moisture was assumed to be that of water at $25^{\circ} \mathrm{C}$; and the heat capacities of the flue gases were calculated using three-term polynomials valid over the range of $0^{\circ}$ to $3500^{\circ} \mathrm{C}$ (Hougan et al. 1954).

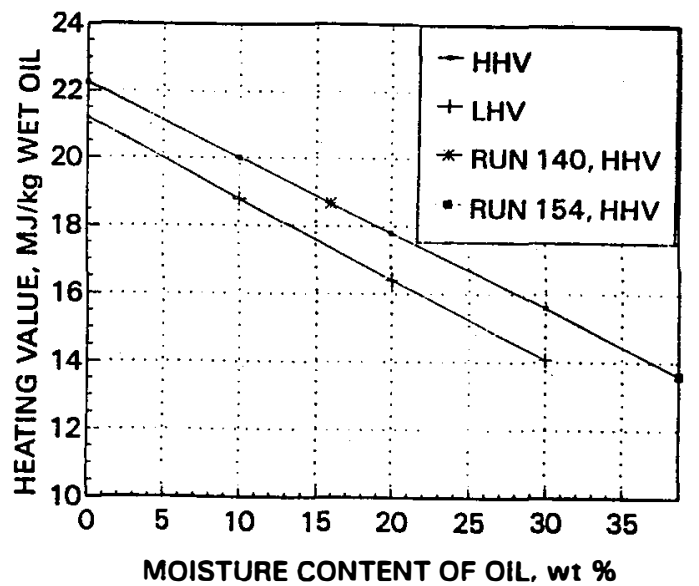

Figure 5.

\begin{abstract}
Effect of moisture in biocrude oil on heating value
\end{abstract}

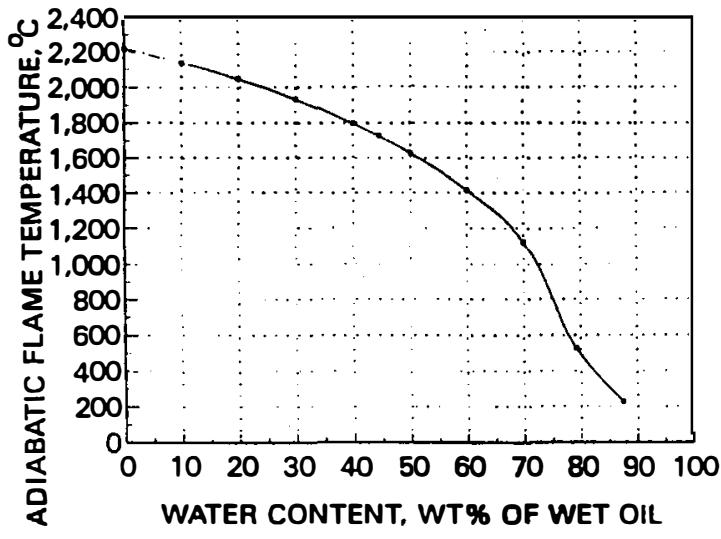

Figure 6.

Increasing the moisture content of the biocrude from $20 \%$ to $30 \%$ by weight (wet oil basis), only decreased the calculated flame temperature from $2045^{\circ} \mathrm{C}$ to $1934^{\circ} \mathrm{C}$. This $111^{\circ} \mathrm{C}$ decrease in flame temperature will lower the amount of energy available from the process. If the exiting flue gas temperature is assumed to be $250^{\circ} \mathrm{C}\left(482^{\circ} \mathrm{F}\right)$, this $10 \%$ increase in moisture in the biocrude will reduce the amount of energy available by only $2.7 \%$ from burning the same amount of biocrude (on a dry oil basis). Thus, although the effect is not negligible, it is very small in the expected range of moisture contents in biocrude oils.

In actual practice, the biocrude producer will probably produce a biocrude product that has a slightly lower moisture content than allowed and then add water, or methanol, or both to it to bring it up to "specification." If this adjustment is made to the final product, the allowable range of moisture content, viscosity, and LHV in the biocrude can be reduced and a more consistent oil produced.

\section{SUMMARY AND CONCLUSIONS}

NREL's vortex pyrolysis reactor has been used to develop hot-gas filtration technology specific to the needs of biomass pyrolysis. These needs are different from other high-temperature filter applications in that the gas and vapor residence time through the filtering device is an important consideration. Low temperatures and residence times are required to preserve high biocrude oil yields at the temperatures necessary for filtration. Reactions in the baghouse affect both the chemistry and yields of the resulting biocrude oils. 
Total alkali metal levels of around $10 \mathrm{ppm}$ were reproducibly shown on two separate experimental runs in which reasonably good process control was achieved. This may be the lower limit obtainable with conventional filtration technology. The viscosity of the as-produced oils met the viscosity requirements for ASTM \#4 diesel and fuel oils. Aging at $90^{\circ} \mathrm{C}$ indicates that this oil can be heated at up to $90^{\circ} \mathrm{C}$ to reduce viscosity for a few hours without excessive polymerization.

In this series of three runs, the yields of wet organic condensates were progressively increased from $51 \%$ to $56 \%$ to $61 \%$ by weight of the bone-dry poplar feed (36\% to $41 \%$ to $49 \%$ by weight of dry organic oil yield). This increase in yields is attributed to a more complete pyrolysis with a higher temperature carrier gas, not recycling condensates for temperature control, and lowering of the baghouse temperatures to preserve the delicate oxygenated pyrolysis oil vapors. In addition, the removal of the bulk of the char with the addition of two char cyclone separators upstream of the baghouse may have been instrumental in reducing char yields and increasing organic oil yields. Further reduction of the gaseous residence time in the baghouse should be investigated.

By adjusting the moisture content to a specified limit, or by adding small amounts of methanol, or both to biocrude oil. the viscosity, LHV, flame temperature, etc., can be modified to result in a more reproducible biocrude oil product having a higher value. International specifications need to be developed for biocrude oil--if we are to make progress in the commercialization of this product. This would logically result in different grades of biocrude fuel oils that would be similar to those for petroleum fuel oils.

\section{REFERENCES}

Agblevor, F. A.; Besler, S.; Montagne, D.; and Evans R.J. (1995), "Influence of Inorganic Compounds on Char Formation and Quality of Fast Pyrolysis Oils," ACS 209th National Meeting, Anaheim, CA, April 2 to 5.

Bakhshi, N.N. and Adjaye, J.D. (1994), "Properties and Characteristics of Ensyn Bio- Oil," Proceedings Specialists Workshop on Biomass Pyrolysis Oil Properties and Combustion, Estes Park, CO., Sept. 26 to 28. NREL, Golden, CO, 80401. CP-430-7215, pp. 54-66.

Beckman, D.; Elliott, D.C.; Gevert, B.; Hörnell, C.; Kjellström, B.; Östman, A.; Solantausta, Y.; and Tulenheimo, V. (1990), Techno-economic Assessment of Selected Biomass Liquefaction Processes, Technical Research Centre of Finland, Research Report 697.

Boroson, M.L.; Howard, J.B.; Longwell, J.P.; and Peters, W.A. (1989), "Heterogeneous Cracking of Wood Pyrolysis Tars over Fresh Wood Char Surfaces," Energy and Fuels, 3, pp.735-740.

Cottam, M-L. and Bridgwater, A.V. (1994), "Techno-economics of Pyrolysis Oil Production and Upgrading," in Advances in Thermochemical Biomass Conversion, A.V. Bridgwater, ed., Blackie Academic, London, England, pp. 1343-1358.

Cuevas, A.; Reinoso, C.; and Scott, D. (1994), "The Production and Handling of WFPP Bio-oil and it's Implications for Combustion", Proceedings: Specialists Workshop on Biomass Pyrolysis Oil Properties and Combustion, Estes Park, CO. Sept 26-28, op. cit., pp.151-156. 
Diebold, J.P. (1985), The Cracking Kinetics of Depolymerized Biomass Vapors in a Continuous, Tubular Reactor, Thesis T-3007, Colorado School of Mines, Golden, CO, 80401.

Diebold, J. and Scahill, J. (1988), "Production of Primary Pyrolysis Oils in a Vortex Reactor," in Pyrolysis Oils from Biomass, E.J. Soltes and T.A. Milne, eds., ACS Symposium Series 376, pp. 3140.

Diebold, J.P.; Czernik, S.; Scahill, J.; Phillips, S.D.; and Feik, C.J. (1994),"Hot Gas Filtration to Remove Char from Pyrolysis Vapors Produced in the Vortex Reactor at NREL," Proceedings of the Specialists Workshop on Biomass Pyrolysis Oil Properties and Combustion, Estes Park, CO, September 26-28, op.cit., pp. 90-108.

Elliott, D.C. (1994), "Water, Alkali, and Char in Flash Pyrolysis Oils," Biomass and Bioenergy, I, pp.179-186.

Hougan, O.A.; Watson, K.M.; and Ragatz, R.A. (1954), Chemical Process Principles. Part 1. Material and Energy Balances, Second ed., John Wiley and Sons, p. xxiii.

Mok, W.S.; Antal, M.J.; Szabo, P.; Varhegyi, G.; and Zelei, B. (1992), "Formation of Charcoal from Biomass in a Sealed Reactor," Ind. Eng. Chem. Res., 31, pp. 1162-1166.

Moses, C.A. and H. Bernstein (1994), Impact of the Use of Biomass-Derived Fuels in the Gas Turbines for Power Generation, NREL/TP-430-6085, National Renewable Energy Laboratory, Golden, CO.

Siau, J.F.(1984), Transport Properties in Wood, Springer-Verlag, p.14.

Tippee, R. and Beck, R.J. (1995) "Politics Has a Strong Say in Who Benefits From Oil," Oil Gas J., April 3, pp. 41-53. 